\title{
Suplementação com farelo de girassol para ovinos alimentados com silagem de bagaço de sorgo sacarino
}

\author{
Sunflower meal supplementation to wethers fed sorghum bagasse silage
}

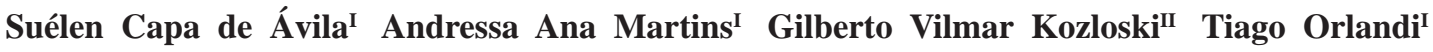 \\ Mariana Patricia Mezzomo ${ }^{\mathrm{III}}$ Cristiano Miguel Stefanello ${ }^{\mathrm{III}}$ Fernanda Hentz \\ Pablo de Souza Castagnino ${ }^{\mathrm{III}}$
}

RESUMO

Seis ovinos Texel $\times$ Corriedale $(43,6 \pm 4,4 \mathrm{~kg}$ de peso corporal (PC)), alimentados ad libitum com silagem de bagaço de sorgo sacarino (Sorghum bicolor (L.) Moench ssp. saccharatum), foram usados em um experimento em duplo Quadrado Latino $3 \times 3$ para avaliar o efeito nutricional da suplementação com níveis de farelo de girassol (0, 7 ou $14 \mathrm{~g} \mathrm{~kg}^{-1}$ de PC). Uma solução (8\%, $p / v)$ de ureia e sulfato de amônio (9:1, respectivamente) foi misturada à silagem no momento do fornecimento aos animais, em todos os tratamentos, numa proporção de $50 \mathrm{ml}$ de solução $\mathrm{kg}^{-1}$ de silagem. O consumo total de matéria seca (MS), matéria orgânica (MO), fibra em detergente neutro (FDN) e de carboidratos não fibrosos (CNF), assim como o consumo de MS da silagem e de MO digestível, foram positivamente afetados $(P<0,05)$ pelo aumento da suplementação com farelo de girassol. A digestibilidade da FDN não foi afetada pelos tratamentos, enquanto que a digestibilidade aparente da MS e da MO foi linearmente $(P<0,05)$ incrementada pela suplementação. A eficiência de síntese proteica microbiana ruminal não foi influenciada pelos tratamentos, enquanto que o consumo, a digestibilidade, a excreção urinária e a retenção de $N$, assim como a síntese de proteína microbiana ruminal, foram linearmente e positivamente afetados pela suplementação $(P<0,05)$. Em conclusão, a suplementação com farelo de girassol impacta positivamente a utilização da silagem de bagaço de sorgo sacarino e a oferta de nutrientes para ovinos.

Palavras-chave: biocombustíveis, co-produtos, consumo, digestibilidade, síntese de proteína microbiana, retenção de $\mathrm{N}$.

\section{ABSTRACT}

Six Texel $\times$ Polwarth $(43.6 \pm 4.4 \mathrm{~kg}$ of body weight $(B W)$ ) wethers fed ad libitum sorghum bagasse silage (Sorghum bicolor (L.) Moench ssp. saccharatum) were used in a replicated $3 \times 3$ Latin Square experiment to evaluate the nutritional effect of supplementing levels of sunflower meal $\left(0,7\right.$ or $14 \mathrm{~g} \mathrm{~kg}^{-1}$ de BW). In all treatments the urea plus ammonium sulphate (9:1, respectively) solution $(8 \%, \mathrm{p} / \mathrm{v})$ was mixed to silage at feeding at a rate of $50 \mathrm{ml}$ $k^{-1} g$ of silage. Total dry matter (DM), organic matter (OM) neutral detergent fibre (NDF) and non-fibre carbohydrates (NFC) intake, as well as DM intake from silage and digestible OM intake were positively affected $(P<0.05)$ by increased levels of sunflower meal supplementation. The NDF digestibility was not affected by treatments whereas the apparent DM and OM digestibility were linearly increased $(P<0.05)$ due supplementation. The efficiency of ruminal microbial protein synthesis was not affected by treatments whereas $N$ intake, digestibility, urinary excretion and retention as well as rumen microbial protein synthesis increased linearly $(P<0.05)$ at increased levels of supplementation. In conclusion, sunflower meal supplementation positively impacts sorghum silage utilization and nutrients supply to wethers.

Key words: biofuel, byproduct, intake, digestibility, microbial protein synthesis, $N$ retention.

\section{INTRODUÇÃO}

A produção de biocombustíveis no Brasil cresce continuamente em função de incentivos governamentais e resulta na produção de vários coprodutos com potencial de uso na alimentação animal. Entre estes, incluem-se o farelo de girassol, coproduto da extração do óleo, e o bagaço de sorgo sacarino, coproduto da produção de álcool. O farelo de girassol caracteriza-se como suplemento concentrado com alto teor de proteína degradável no rúmen (NRC, 2007), mas também contém alto teor

IPrograma de Pós-graduação em Zootecnia, Universidade Federal de Santa Maria (UFSM), Santa Maria, RS, Brasil.

IIDepartamento de Zootecnia, UFSM, Cidade Universitária, Bairro Camobi, 97105-900, Santa Maria, RS, Brasil. E-mail: kozloski@smail.ufsm.br. Autor para correspondência.

"IIGraduação em Zootecnia, UFSM, Santa Maria, RS, Brasil. 
de fibra em detergente neutro (FDN). O bagaço de sorgo sacarino, por sua vez, tem alto teor de FDN e teor insignificante de $\mathrm{N}$, o que seria o principal fator limitante do seu valor nutricional. Em função disso, dietas a base de bagaço de sorgo devem obrigatoriamente incluir ingredientes suplementares ricos em $\mathrm{N}$.

O efeito da suplementação sobre o consumo do volumoso e de nutrientes totais e, dessa forma, sobre o desempenho animal, é variável e depende de vários fatores, incluindo composição química da forragem, tipo e nível de suplementação e potencial genético do animal (MOORE et al., 1999). Quando o teor de $\mathrm{N}$ do volumoso é baixo, há limitação do crescimento e atividade dos microorganismos ruminais. Nessa situação, a suplementação com proteína degradável pode aumentar o consumo e a digestibilidade do volumoso e melhorar o desempenho animal (PATERSON et al., 1994). Contudo, o impacto da suplementação nitrogenada depende do nível de suplementação e se a fonte de $\mathrm{N}$ é proteína verdadeira ou N não proteico (CARRO \& MILLER, 1999; BRODERICK \& REYNAL, 2009). Estudos in vitro demonstraram que o crescimento da microflora ruminal é estimulado pela presença de aminoácidos (ARGYLE \& BALDWIN, 1989), de modo que a degradação da FDN é aumentada pela suplementação com fontes de proteína verdadeira degradável no rúmen (COSTA et al., 2008). Além disso, embora a maior parte dos aminoácidos livres são fermentados no rúmen (BARKER, 1981), a inclusão de fontes de proteína verdadeira degradável na dieta pode resultar em quantidades significativas de aminoácidos e peptídeos liberados no fluído ruminal pela proteólise bacteriana, parte dos quais pode fluir com a digesta e ser absorvida no intestino delgado (VOLDEN et al., 2002). Contudo, não é conhecido se, ou em qual grau, a inclusão de farelo de girassol potencializaria a oferta de nutrientes para animais alimentados com bagaço de sorgo.

Objetivou-se avaliar o efeito nutricional da suplementação com níveis de farelo de girassol para ovinos alimentados com silagem de bagaço de sorgo sacarino mais ureia.

\section{MATERIAL E MÉTODOS}

Foram utilizados seis ovinos Texel $\times$ Corriedale $(43,6 \pm 4,4 \mathrm{~kg}$ de peso corporal (PC)), alojados individualmente em gaiolas de metabolismo, em um delineamento Quadrado Latino $3 \times 3$ replicado. As dietas experimentais foram silagem de bagaço de sorgo sacarino (Sorghum bicolor (L.) Moench ssp. saccharatum) ad libitum sem suplementação ou silagem ad libitum mais suplementação com farelo de girassol a níveis de 7 ou $14 \mathrm{~g} \mathrm{~kg}^{-1}$ de PC. O sorgo sacarino foi cortado em estádio final de crescimento (i.e. apresentava grãos farináceos), o qual foi prensado para extração do caldo e triturado. O material residual foi então colocado em tonéis metálicos com capacidade para 200 litros, compactado através de pisoteio, vedado e ensilado durante aproximadamente 30 dias até o início do experimento. A composição química da silagem e do suplemento é apresentada na tabela 1. Embora não tenha sido feita nenhuma avaliação físico-química, após abertura dos tonéis, o material ensilado apresentava cor e odor característico de silagem adequadamente fermentada e conservada. Uma solução $(8 \%, \mathrm{p} / \mathrm{v})$ de ureia e sulfato de amônio (9:1, respectivamente) foi misturada à silagem no momento do fornecimento aos animais, em todos os tratamentos, numa proporção de $50 \mathrm{ml}$ de solução $\mathrm{kg}^{-1}$ de silagem, com o propósito de elevar o teor de proteína bruta do volumoso para em torno $8 \%$ (base matéria seca (MS)). Os animais tiveram acesso permanente à água e sal mineral contendo $\left(\mathrm{g} \mathrm{kg}^{-1}\right)$ : Ca: 100, P: 45, S: 4,12, Na: 205, Co: 0,025, Cu: 0,450, Fe: 1.5, I: 0,05, Mn : 1.0, SE: 0.009, Zn: 2,52 e F: 0,45.

Os períodos experimentais foram de 15 dias, sendo 10 dias de adaptação à dieta, seguidos de 5 dias de coleta de amostras. Os alimentos foram fornecidos duas vezes ao dia (08:00h e 16:30h), sendo o concentrado oferecido antes do volumoso para assegurar ausência de sobras do suplemento. A quantidade de silagem ofertada foi ajustada, diariamente, antes da refeição da manhã, com base no consumo observado no dia anterior, de modo que houvesse sobras de 100 a $200 \mathrm{~g} \mathrm{~kg}^{-1}$ da silagem ofertada para cada animal. O alimento ofertado foi

Tabela 1 - Composição química da forragem e do suplemento.

\begin{tabular}{lcc}
\hline & ---------Ingredientes---------- \\
& Silagem & Farelo de girassol \\
\hline Matéria seca (MS), $\mathrm{g} \mathrm{kg}^{-1}$ & 383 & 874 \\
Composição ( $\mathrm{g} \mathrm{kg}^{-1}$ de MS) & & \\
Matéria orgânica & 971 & 944 \\
N total & 6,5 & 53,4 \\
Fibra em detergente neutro & 630 & 380 \\
Fibra em detergente ácido & 414 & 276 \\
Lignina em detergente ácido & 52 & 77 \\
Extrato etéreo & 46 & 24 \\
Carboidratos não fibrosos & 263 & 231 \\
N insolúvel em detergente neutro & 1,5 & 4,0 \\
N insolúvel em detergente ácido & 1,1 & 2,6 \\
\hline
\end{tabular}


pesado e amostrado diariamente do $10^{\circ}$ ao $15^{\circ}$ dia de cada período experimental. As sobras e as fezes de cada animal foram coletadas, pesadas e armazenadas $\left(-20^{\circ} \mathrm{C}\right)$ cumulativamente num mesmo recipiente durante o período de coletas. Ao final de cada período, as sobras e as fezes foram descongeladas, misturadas e foi retirada uma amostra (10\% do total) composta por animal e período. Amostras da dieta, sobras e fezes foram secas em estufa com ventilação forçada de ar $\left(55^{\circ} \mathrm{C}\right)$ por pelo menos $72 \mathrm{~h}$, moídas em peneira com porosidade de $1 \mathrm{~mm}$ (moinho Willey, Arthur H. Thomas, Philadelphia, PA) e armazenadas para posterior análise. A urina foi coletada em recipientes contendo $100 \mathrm{~mL}$ de uma solução de $\mathrm{H}_{2} \mathrm{SO}_{4} 7,2 \mathrm{~N}$. Diariamente, o volume total foi mensurado e, $\operatorname{logo}$ após, retirou-se uma amostra de 1\% do volume total, a qual foi transferida para um balão volumétrico de $50 \mathrm{~mL}$, completado o volume com água destilada e armazenada $\left(-20^{\circ} \mathrm{C}\right)$ para posterior análise.

O teor de matéria seca(MS) foi determinado por secagem a $110^{\circ} \mathrm{C}$ por pelo menos 8 horas. A matéria mineral (MM) foi determinada após combustão a $600^{\circ} \mathrm{C}$ por 3 horas, e a matéria orgânica (MO), por diferença de peso. O N total foi determinado pelo método de Kjeldahl (Método 984.13, AOAC, 1997). $\mathrm{O}$ teor de FDN foi analisado com $\alpha$-amilase estável ao calor e expresso excluído das cinzas, utilizandose o método descrito por MERTENS (2002), exceto que as amostras foram pesadas em sacos de poliéster (porosidade de $25 \mu$ ) e tratadas com detergente neutro em autoclave a $110^{\circ} \mathrm{C}$ por 40 minutos (SENGER et al., 2008). As concentrações de fibra em detergente ácido (FDA) e lignina em detergente ácido (LDA) foram analisadas segundo o Método 973.18 da AOAC (1997) exceto que as amostras foram pesadas em sacos de poliéster (porosidade de $25 \mu$ ) e tratadas com detergente ácido em autoclave a $110^{\circ} \mathrm{C}$ por 40 minutos (SENGER et al., 2008). As análises de $\mathrm{N}$ insolúvel em detergente ácido (NIDA) e $\mathrm{N}$ insolúvel em detergente neutro (NIDN) foram realizadas de acordo com LICITRA et al. (1996). A concentração de extrato etéreo (EE) foi determinada em um sistema de refluxo contínuo (Soxtherm 2000 S 306 M, Gerhardt; Königswinter, Alemanha) com éter etílico a $180^{\circ} \mathrm{C}$ por 2 horas. O conteúdo de carboidratos não fibrosos (CNF, $\mathrm{g} \mathrm{kg}^{-1}$ ) foi calculado como: MO-[(FDN$(\mathrm{NIDN} \times 6,25))+(\mathrm{N} \times 6,25)+\mathrm{EE}]$, de acordo com VAN SOEST et al. (1991).

As concentrações de alantoína e ácido úrico na urina foram determinadas colorimetricamente, de acordo com a técnica de CHEN \& GOMES (1992). O ácido úrico foi determinado usando um Kit comercial
(LABTEST, Lagoa Santa, MG, Brasil), após xantina e hipoxantina serem convertidas a ácido úrico com xantina oxidase. Dessa forma, os teores de ácido úrico foram calculados como a soma de ácido úrico, xantina e hipoxantina (convertidos a ácido úrico) e os derivados de purina totais (DP), como a soma do ácido úrico e alantoína.

A quantidade de purinas absorvidas $(X$, mmol $\left.\operatorname{dia}^{-1}\right)$, correspondente à quantidade de DP excretados $(Y, \mathrm{mmol} / \mathrm{dia})$, foi calculada pela equação de CHEN \& GOMES (1992): $\mathrm{Y}=0,84 \mathrm{X}+(0,150$ $\left.\mathrm{PV}^{0,75} \mathrm{e}^{-0,25 \mathrm{X}}\right)$. O cálculo de $X$, baseado no valor de $Y$, foi feito utilizando-se o processo iterativo de Newton-Raphson como: $\mathrm{X}_{(\mathrm{n}+1)}=\mathrm{X}_{\mathrm{n}}-[((0,84 \mathrm{X}+(0,150$ $\left.\left.\left.\left.\mathrm{PV}^{0,75} \mathrm{e}^{-0,25 \mathrm{X}}\right)\right)-\mathrm{Y}\right) /\left(0,84-\left(0,038 \mathrm{PV}^{0,75} \mathrm{e}^{-0,25 \mathrm{X}}\right)\right)\right]$. A oferta duodenal de $\mathrm{N}$ microbiano (Nm) foi estimada como: $\mathrm{Nm}$ $\left(\mathrm{g} \mathrm{dia}^{-1}\right)=70 \mathrm{X} /(0,116 \times 0,83 \times 1000)=0,727 \mathrm{X}$, assumindo que a digestibilidade das purinas microbianas é 0,83 , o conteúdo de $\mathrm{N}$ nas purinas é de $70 \mathrm{mg} \mathrm{mmol}^{-1}$ e a proporção $\mathrm{N}$ de purinas/ $\mathrm{N}$ microbiano é 0,116 (CHEN \& GOMES, 1992).

A digestibilidade verdadeira da MO (DVMO) foi estimada considerando-se que as frações solúveis em detergente neutro das fezes são de origem endógena e somente a fração FDN das fezes é de origem alimentar (VAN SOEST, 1994), como segue: $\mathrm{DVMO}=\left(\right.$ consumo de $\mathrm{MO}\left(\mathrm{g} \mathrm{dia}^{-1}\right)-$ FDN fecal $\left.\left(\mathrm{g} \mathrm{dia}^{-1}\right)\right) /$ consumo de $\mathrm{MO}\left(\mathrm{g} \mathrm{dia}^{-1}\right)$.

A digestibilidade verdadeira do nitrogênio (DVN) foi calculada considerando que somente o NIDN fecal é de origem alimentar da seguinte forma: DVN $=\left(\right.$ consumo de $\mathrm{N}\left(\mathrm{g} \mathrm{dia}^{-1}\right)-\mathrm{NIDN}$ fecal $\left.\left(\mathrm{g} \mathrm{dia}^{-1}\right)\right) /$ consumo de $\mathrm{N}\left(\mathrm{g} \mathrm{dia}^{-1}\right)$.

Os dados foram analisados utilizando o procedimento GLM do programa Statistical Analysis System (SAS, 2001), de acordo com o modelo: $Y_{\mathrm{ijkl}}=\mu+A_{\mathrm{i}}+P_{\mathrm{j}}+T_{\mathrm{k}}+\varepsilon_{\mathrm{ijk} k \mathrm{l}}$, em que $\mathrm{Y}$ é a variável dependente, A é o efeito aleatório de animal, $\mathrm{P}$ é o efeito aleatório de período, $\mathrm{T}$ é o efeito fixo de tratamento e $\varepsilon$ é o erro residual. $\mathrm{O}$ efeito de tratamento foi analisado por regressão linear.

\section{RESULTADOS E DISCUSSÃO}

O consumo voluntário é geralmente a variável mais relevante, influenciando a oferta de nutrientes e o desempenho dos ruminantes e, geralmente, a suplementação com concentrado exerce um efeito positivo sobre o consumo da dieta total e um efeito substitutivo sobre o consumo de forragem (TAMMINGA \& HOFF, 1999). De fato, os consumos de MS, MO, FDN e de CNF foram positivamente 
afetados pelo aumento da suplementação com farelo de girassol (Tabela 2). Contudo, diferente do esperado, o farelo de girassol exerceu um efeito aditivo $(\mathrm{P}<0,05)$ sobre o consumo do volumoso. Comparado ao tratamento sem suplementação, os animais suplementados consumiram em média $86 \%$ mais MS total e $8 \%$ mais MS da silagem. O nível de consumo de FDN, principalmente de sua fração indigestível, geralmente tem sido aceito como o principal fator determinante do consumo em dietas baseadas em forragem, uma vez que está diretamente relacionada à distensão física do retículo-rúmen (VAN SOEST, 1994). No presente estudo, a digestibilidade da FDN não foi afetada pela suplementação (Tabela 2), de modo que o consumo de FDN indigestível aumentou com o aumento da ingestão do suplemento. Sendo assim, é improvável que o enchimento ruminal tenha sido o fator que limitou o consumo pelos animais que receberam somente silagem mais ureia. A explicação para esse efeito não é aparente e vários fatores podem estar concomitantemente envolvidos. Embora o pH da silagem não tenha sido medido, o aspecto de bom grau de conservação indica que o seu valor era em torno de 4,0, o que pode deprimir o consumo. De outra forma, FORBES (2007) reportou que dietas pobres em $\mathrm{N}$ podem limitar o consumo, devido a imbalanços na oferta de aminoácidos e substratos energéticos aos tecidos do animal. Por outro lado, é possível que a suplementação tenha impactado positivamente $o$ peristaltismo e a taxa de passagem da digesta pelo trato digestivo, estimulando o consumo.

A digestibilidade aparente da MS e da $\mathrm{MO}$, assim como a digestibilidade verdadeira da $\mathrm{MO}$, aumentou linearmente $(\mathrm{P}<0,05)$ com a inclusão do farelo de girassol na dieta (Tabela 2). Como consequência dos efeitos positivos sobre o consumo e digestibilidade, o consumo de MO digestível também aumentou linearmente $(\mathrm{P}<0,05)$ com a suplementação. De fato, enquanto que a suplementação com concentrados ricos em CNF usualmente exerce efeito negativo sobre o consumo de forragem, devido principalmente à queda do $\mathrm{pH}$ ruminal e consequente redução da digestibilidade da fibra (TAMMINGA, 1993; PATERSON et al., 1994), estudos in vitro demonstraram que o crescimento da microflora ruminal e a digestibilidade da fibra são estimulados pela presença de aminoácidos (ARGYLE \& BALDWIN, 1989) ou de proteína degradável (COSTA et al., 2008). O farelo de girassol tem alto teor de proteína degradável e de FDN e, consequentemente, teor relativamente baixo de CNF. Em função disso, o consumo de CNF aumentou em valores absolutos, mas não variou como proporção do alimento ingerido (i.e. em torno de $25 \%$ da MS total).

Tabela 2 - Consumo e digestibilidade em ovinos alimentados com dietas a base de silagem de bagaço de sorgo mais ureia e suplementados com níveis de farelo de girassol.

\begin{tabular}{|c|c|c|c|c|c|}
\hline & \multicolumn{3}{|c|}{----Farelo de girassol ( $\mathrm{g} \mathrm{kg}^{-1}$ de peso corporal)----------- } & \multirow{2}{*}{$\mathrm{EPM}^{1}$} & \multirow{2}{*}{$\mathrm{P}^{2}$} \\
\hline & 0 & 7 & 14 & & \\
\hline \multicolumn{6}{|l|}{ Consumo de matéria seca } \\
\hline $\mathrm{g} \mathrm{dia}^{-1}$ & 539 & 897 & 1137 & 11,8 & $<0,001$ \\
\hline $\mathrm{g} \mathrm{kg}^{-1}$ de peso corporal & 12 & 21 & 26 & 0,05 & $<0,001$ \\
\hline \multicolumn{6}{|l|}{ Consumo total $\left(\mathrm{g} \mathrm{dia}^{-1}\right)$ : } \\
\hline Matéria orgânica & 521 & 860 & 1085 & 11,2 & $<0,001$ \\
\hline Fibra em detergente neutro & 321 & 469 & 547 & 6,4 & $<0,001$ \\
\hline Carboidratos não fibrosos & 139 & 221 & 273 & 2,56 & $<0,001$ \\
\hline Matéria orgânica digestível & 268 & 502 & 650 & 11,1 & $<0,001$ \\
\hline \multicolumn{6}{|c|}{ Consumo de matéria seca $\left(\mathrm{g} \mathrm{dia}^{-1}\right)$} \\
\hline Forragem & 523 & 539 & 591 & 10,1 & 0,616 \\
\hline Concentrado & 0,00 & 306 & 613 & 12,6 & $<0,001$ \\
\hline \multicolumn{6}{|l|}{ Digestibilidade aparente } \\
\hline Matéria seca & 0,49 & 0,57 & 0,58 & 0,02 & 0,002 \\
\hline Matéria orgânica & 0,51 & 0,58 & 0,60 & 0,02 & 0,005 \\
\hline Fibra em detergente neutro & 0,39 & 0,45 & 0,46 & 0,02 & 0,205 \\
\hline $\mathrm{DVMO}^{3}$ & 0,63 & 0,70 & 0,72 & 0,01 & 0,001 \\
\hline
\end{tabular}

${ }^{1}$ Erro padrão das médias, em que $\mathrm{n}=6$ por tratamento.

${ }^{2}$ Probabilidade do efeito linear pela análise de regressão.

${ }^{3}$ Digestibilidade verdadeira da matéria orgânica. 
Desse modo, embora especulativo, é improvável que a suplementação tenha reduzido o $\mathrm{pH}$ ruminal a níveis limitantes. De outro modo, se existiu efeito negativo de $\mathrm{pH}$ sobre o crescimento e atividade das bactérias fibrolíticas ruminais, esse efeito foi contrabalançado pelo efeito estimulatório causado pelo provável aumento da disponibilidade de aminoácidos no rúmen.

O consumo total, a digestibilidade, a excreção urinária e a retenção de $\mathrm{N}$, assim como o fluxo duodenal de $\mathrm{N}$ microbiano aumentaram linearmente $(\mathrm{P}<0,05)$ com o aumento dos níveis de farelo de girassol na dieta (Tabela 3 ). O fluxo duodenal de $\mathrm{N}$ microbiano foi diretamente relacionado com o consumo de MO digestível, de modo que a eficiência de síntese proteica microbiana ruminal não foi afetada pelos tratamentos. Esses resultados também representam indicativo de que não houve redução significativa do $\mathrm{pH}$ ruminal pela ingestão do farelo de girassol.

As ofertas de energia e aminoácidos estão incluídas entre os fatores que afetam a retenção de $\mathrm{N}$ pelo animal. Por exemplo, quando a necessidade de energia é mais alta do que o consumo ou quando a disponibilidade de aminoácidos para os tecidos é proporcionalmente mais alta do que a oferta de energia, a proporção de aminoácidos absorvidos que são oxidados ou utilizados na gliconeogênese hepática aumenta, reduzindo a retenção de N (SUN \& ZHAO, 2009). No presente estudo, a retenção de $\mathrm{N}$ foi diretamente proporcional ao consumo de MO digestível. Contudo, a proporção do $\mathrm{N}$ ingerido que foi retido aumentou de $14 \%$ nos animais não suplementados para $46 \%$ nos animais que receberam o nível mais alto de suplementação com farelo de girassol. Isso indica que ambos, a oferta de energia e aminoácidos, contribuíram para melhorar a eficiência do uso do $\mathrm{N}$ dietético.

O presente experimento foi proposto para avaliar o impacto nutricional da inclusão de proporções ou níveis de coprodutos da extração de biocombustíveis na alimentação de ruminantes, sem ajuste do teor de proteína bruta das dietas. Em função disso, o consumo e a excreção de $\mathrm{N}$ foram relativamente excessivos no tratamento com nível mais alto de suplementação, o que nutricionalmente não é recomendado e pode impactar negativamente o ecossistema. Entretanto, níveis similares de excreção e deposição de $\mathrm{N}$ podem ter efeitos diferentes para o meio ambiente, dependendo do ecossistema que eles afetam. Por exemplo, a maior parte das áreas tropicais utilizadas para cultivos ou pastagens são deficientes quanto à disponibilidade de $\mathrm{N}$ no solo. Nessas situações, o aumento da entrada de $\mathrm{N}$ no sistema a partir de coprodutos das sementes oleaginosas pode ter um impacto positivo sobre a produtividade e sustentabilidade desses ecossistemas como um todo (OLTJEN \& BECKETT, 1996).

\section{CONCLUSÃO}

A oferta de nutrientes aos animais e o potencial nutricional da silagem de bagaço de sorgo sacarino são positivamente impactados pela suplementação com farelo de girassol.

\section{COMITÊ DE ÉTICA E BIOSSEGURANÇA}

Declaro ainda que ao final do experimento os animais foram integrados a um sistema de produção de ovinos mantidos em pastagem.

Tabela 3 - Consumo, digestibilidade, excreção urinária, retenção de $\mathrm{N}$ e fluxo duodenal de $\mathrm{N}$ microbiano em ovinos alimentados com dietas a base de silagem de bagaço de sorgo mais ureia e suplementados com níveis de farelo de girassol.

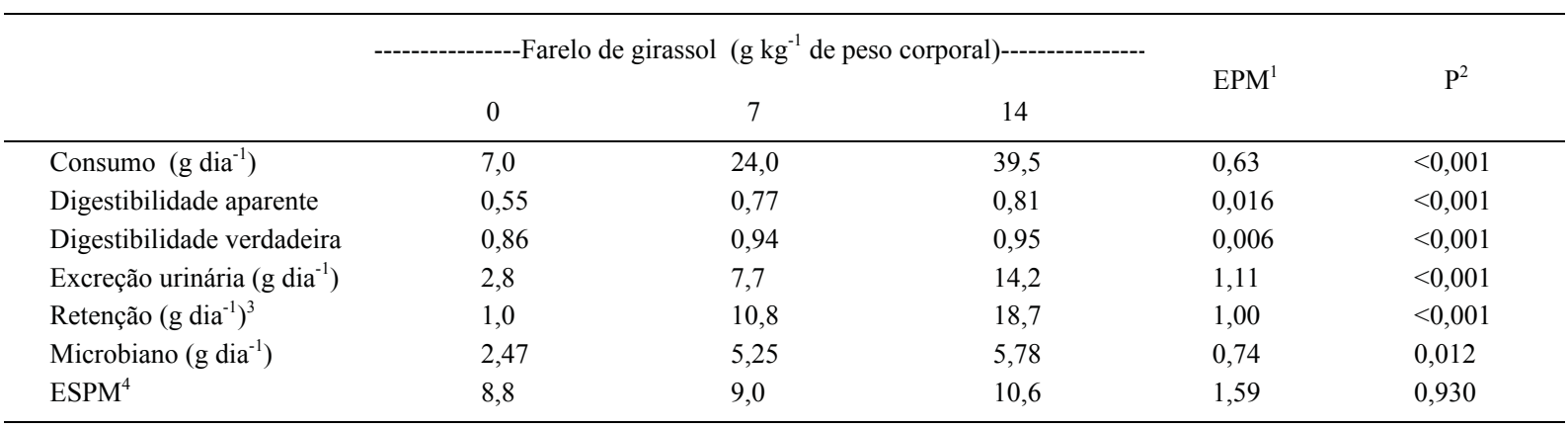

\footnotetext{
${ }^{1}$ Erro padrão das médias, em que $\mathrm{n}=6$ por tratamento.

${ }^{2}$ Probabilidade do efeito linear pela análise de regressão.

${ }^{3} \mathrm{~N}$ consumido $-(\mathrm{N}$ fecal $+\mathrm{N}$ urinário $)$.

${ }^{4}$ Eficiência da síntese proteica microbiana ruminal ( $\mathrm{g} \mathrm{N}$ microbiano/kg matéria orgânica digestível).
}

Ciência Rural, v.43, n.7, jul, 2013. 


\section{REFERÊNCIAS}

ARGYLE, J.L.; BALDWIN, R.L. Effects of amino acids and peptides on rumen microbial growth yields. Journal of Dairy Science, v.72, p.2017-2027, 1989. Disponível em: <http:// download.journals.elsevierhealth.com/pdfs/journals/0022-0302/ PIIS0022030289793255.pdf>. Acesso em: 23 out. 2012.

AOAC (ASSOCIATION OF OFFICIAL ANALYTICAL CHEMISTS). Official methods of analysis. 16.ed. Gaithersburg: AOAC International, 1997. 1298p.

BARKER, A. Amino acid degradation by anaerobic bacteria Annual Reviews of biochemistry, v.50, p.23-40, 1981. Disponível em: $\quad<$ http://www.annualreviews.org/doi/pdf/10.1146/annurev. bi.50.070181.000323>. Acesso em: 23 out. 2012.

BRODERICK, G.A.; REYNAL, S.M. Effect of source of rumendegraded protein on production and ruminal metabolism in lactating dairy cows. Journal of Dairy Science, v.92, p.2822-2834, 2009. Disponível em: <http://download.journals.elsevierhealth.com/ pdfs/journals/0022-0302/PIIS0022030209705995.pdf>. Acesso em: 23 out. 2012 . doi: $10.3168 /$ jds.2008-1865.

CARRO, M.D.; MILLER, E.L. Effect of supplementing a fibre basal diet with different nitrogen forms on ruminal fermentation and microbial growth in an in vitro semi-continuous culture system (RUSITEC). British Journal of Nutrition, v.82, p.149-157, 1999. Disponível em: < http://dx.doi.org/10.1017/S0007114599001300>. Acesso em: 23 out. 2012.

CHEN, X.B.; GOMES, M.J. Estimation of microbial protein supply to sheep and cattle based on urinary excretion of purine derivatives - An overview of the technical details. International Feed Resources Unit Rowett Research Institute. Bucksburn Aberdeen, UK: Ocasional publication, 1995. 22p. Disponível em: $<$ http://www.macaulay.ac.uk/IFRU/pdf/chema.pdf $>$. Acesso em: 23 out. 2012 .

COSTA, V.A.C. et al. Degradação in vitro da fibra em detergente neutro de forragem tropical de baixa qualidade em função de suplementação com proteína e/ou carboidratos. Revista Brasileira de Zootecnia, v.37, p.494-503, 2008. Disponível em: <http:// www.scielo.br/pdf/rbz/v37n3/15.pdf>. Acesso em: 23 out. 2012.

FORBES, J.M. A personal view of how ruminant animals control their intake and choice of food: minimal total discomfort. Nutrition Research Reviews, v.20, p.132-146, 2007. Disponível em: <http://dx.doi.org/10.1017/S0954422407797834>. Acesso em: 23 out. 2012.

LICITRA, G. et al. Standardization of procedures for nitrogen fractionation of ruminant feeds. Animal Feed Science and Technology, v.57, p.347-358, 1996. Disponível em: <http://dx.doi. org/10.1016/0377-8401(95)00837-3>. Acesso em: 23 out. 2012.

MERTENS, D.R. Gravimetric determination of amylase-treated neutral detergent fibre in feeds with refluxing beakers or crucibles: a collaborative study. Journal of Association of Official Analytical Chemists, v.85, p.1217-1240, 2002. Disponível em: $<$ http://naldc. nal.usda.gov/download/26403/PDF>. Acesso em: 23 out. 2012.
MOORE, J.E et al. Effects of supplementation on voluntary intake forage, diet digestibility, and animal performance. Journal of Animal Science, v.77, p.122-135, 1999. Disponível em: $<$ http://www.journalofanimalscience.org/content/77/suppl_2/122. citation>. Acesso em: 23 out. 2012.

NRC (NATIONAL RESEARCH COUNCIL). Nutrient requirements of small ruminants. Washington: National Academic, 2007. 362p.

OLTJEN,J.W.; BECKETT, J.L. Role of ruminant livestock in sustainable agricultural systems. Journal of Animal Science, v.74, p.1406-1409, 1996. Disponível em: <http://www.journalofanimalscience.org/ content/74/6/1406>. Acesso em: 23 out. 2012

PATERSON, J.A. et al. The impact of forage quality and supplementation regimen on ruminant animal intake and performance. In. FAHEY JUNIOR, G.C. Forage quality, evaluation and utilization. Madison: ASA, CSSA, SSSA, 1994. p.564-612.

SAS (STATYSTICAL ANALYSIS SYSTEM). Statistical analysis user's guide. Version 8.2. Cary: SAS Institute, 2001. 1686p.

SENGER, C.D. et al. Evaluation of autoclave procedures for fibre analysis in forage and concentrate feedstuffs. Animal Feed Science and Technology, v.146, p.169-174, 2008. Disponível em: $<$ http://dx.doi.org/10.1016/j.anifeedsci.2007.12.008>. Acesso em: 20 out. 2012. doi:10.1016/j.anifeedsci.2007.12.008.

SUN, Y.B.; ZHAO, G.Y. The relationship between the volatile fatty acids supply and the nitrogen retention in growing sheep nourished by total intragastric infusions. Small Ruminant Research, v.81, p.8-12, 2009. Disponível em: <http://dx.doi.org/10.1016/j. smallrumres.2008.10.006>. Acesso em: 24 out. 2012.

TAMMINGA, S. Influence of feeding management on ruminal fibre digestibility. In. JUNG, H.G. et al. Forage cell wall structure and digestibility. Madison: ASA, CSSA, SSSA, 1993. p.571-602.

TAMMINGA, S.; HOFF, G. Feeding systems for dairy cows. In. THEODOROU, M.K.; FRANCE, J. Feeding systems and feed evaluation models. Londres: CABI Publishing, 1999. p.109-127.

VAN SOEST, P.J. et al. Methods for dietary fiber, neutral detergent fiber, and nonstarch polysaccharides in relation to animal nutrition. Journal of Dairy Science, v.74, p.3583-3597, 1991. Disponível em: <http://download.journals.elsevierhealth.com/ pdfs/journals/0022-0302/PIIS0022030291785512.pdf>. Acesso em: 23 out. 2012.

VAN SOEST, P.J. Nutritional ecology of the ruminant. 2.ed. New York: Cornell University, 1994. 476p.

VOLDEN, H. et al. Apparent ruminal degradation and rumen escape of soluble nitrogen fraction in grass and grass silage administered intraruminally to lactating dairy cows. Journal of Animal Science, v.80, p.2704-2716, 2002. Disponível em: <http:// www.journalofanimalscience.org/content/80/10/2704>. Acesso em: 23 out. 2012. 